CIUDAD Y TERRITORIO

ESTUDIOS TERRITORIALES

ISSN(P): 2697-231X; ISSN(E): 2697-2328

Vol. LIII, N.ํ Monográfico 2021

Págs. 27-42

https://doi.org/10.37230/CyTET.2021.M21.02

CC BY-NC-ND

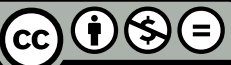

\title{
Emancipación residencial y acceso de los jóvenes al alquiler en España: un problema agravado y su diversidad territorial
}

\author{
Antonio EChAVES-GARCíA ${ }^{(1)}$ \\ Almudena Martínez-del Olmo ${ }^{(2)}$
}

${ }^{(1)}$ Departamento de Sociología de la Universidad de Sevilla

(2) Universidad de Nebrija

Resumen: El presente artículo analiza la relación entre las dinámicas recientes del sistema de provisión de vivienda en España y los comportamientos residenciales de los jóvenes constatándose un agravamiento generalizado de las dificultades de acceso a la vivienda que se vería reflejado a través de la disminución en las tasas de emancipación y el aumento del esfuerzo de acceso a la vivienda en alquiler. Dentro de este contexto global, es posible además establecer pautas diferenciales entre Comunidades Autónomas, de manera que, aquellas que reflejan precios de alquiler comparativamente inferiores a los de la propiedad presentan también mayor porcentaje de hogares en alquiler. Al mismo tiempo, aquellas que muestran una mayor promoción de vivienda protegida en alquiler presentan también tasas de emancipación más altas.

Palabras clave: Sistema de provisión de vivienda; Jóvenes; Emancipación; Comunidades Autónomas.

\section{Residential emancipation and young access to rental housing in Spain: An aggravated problem and its territorial diversity}

ABSTRACT: The following article analyses the relationship between the recent dynamics of the housing provision system in Spain and the residential patterns of young people, confirming a generalized worsening of the difficulties of access to housing that would be reflected through both the decrease of emancipation rates and the growing effort rates to access rental housing. Within this global context, it

Recibido: 26.06.2020; Revisado: 09.10.2020.

Correo electrónico: aechaves@us.es; N.ํ ORCID: https://orcid.org/0000-0001-5217-5003

Correo electrónico: amartinezol@nebrija.es; N. ${ }^{\circ}$ ORCID: https://orcid.org/0000-0001-9865-9257

Los autores agradecen los comentarios y sugerencias realizados por los evaluadores anónimos, que han contribuido a mejorar y enriquecer el manuscrito original. 
is also possible to establish different patterns among Autonomous Communities so that those that reflect rental prices comparatively lower than those of the homeownership market also present a higher percentage of young rental households. At the same time, those showing a higher promotion of subsidised rental housing also have higher emancipation rates.

KEYWORDS: Housing provision system; Young population; Emancipation; Autonomous Communities.

\section{Introducción ${ }^{1}$}

- I I análisis sociológico de la vivienda ha dado lugar a distintas perspectivas y marcos interpretativos, muchas veces complementarios, con casi un siglo de tradición (LEAL, 2018). Una producción científica diversificada que trata de comprender ciertos fenómenos residenciales como hechos sociales indisociables de los aspectos cotidianos y estructurales de la realidad (CORTÉs, 1995), siendo cada realidad social y los atributos que la constituyen, la que determinará un entorno habitacional con características delimitadas (KEMENY, 1992). Estos elementos específicos son los que han permitido entender la vivienda como problemática de análisis (LEAL, 1978), pues la crisis de alojamiento en las sociedades actuales es de tal envergadura que ha llevado al planteamiento de ciertos interrogantes y a tratar de deducir las causas o motivos por los cuales existe una desadecuación tan amplia entre necesidad de vivienda y satisfacción de la misma.

En muchas sociedades occidentales, y en especial en España, el acceso a la vivienda es un problema estructural que impacta en la provisión y en la satisfacción de la necesidad de este bien. Y esto ha constituido la base y ha generado el estudio de hechos socialmente diversificados y estratificados, en los que se recurre a la vivienda y sus diferentes tipologías; tenencias o costes, para explicar procesos de segregación, exclusión, movilidad o desigualdad residencial entre distintos grupos sociales (ECHAVES, 2017a y 2017b; LEAL \& AlguACIL, 2012; MARTíneZ, 2013 y 2018).

Se hablaba antes de los distintos marcos interpretativos y perspectivas que, desde la sociología, han analizado la vivienda y su conexión con la sociedad. Una de estas perspectivas es la del estudio de la provisión de vivienda y los agentes que intervienen en su producción (PRETECEILLE, 1971). Dentro de esta perspectiva, pero con matices específicos, podemos incluir aquellos análisis sobre las distintas maneras en las que el Estado

${ }^{1}$ Este artículo forma parte del proyecto I+D ref. CSO201783968-R «Influencia de los cambios en los regímenes de producción y acceso a la vivienda sobre la reestructuración interviene en el sistema de vivienda; un enfoque político que, formando parte originalmente del paradigma institucional o weberiano (BASSETT \& SHORT, 1980), asigna a las estructuras políticas (y económicas) verdadera capacidad para ejercer influencia en el hecho residencial. Además, constatará la relación entre acusados desequilibrios residenciales, necesidades de vivienda no satisfechas y la actuación de un mercado que, alejado de la neutralidad, persigue intereses propios en un entorno de conflicto, lo que hará necesario la intervención estatal de los modos de producción y de acceso a la vivienda.

De esta forma, el punto de vista institucional en el análisis sociológico de la vivienda resultará del todo oportuno, al considerar al mercado (de vivienda) como el "campo de batalla" de unos intereses que surgirán en el momento en el que se definen unas políticas institucionales concretas. Serán estos factores estructurales los que podrían delimitar diferentes comportamientos en torno a la realidad habitacional y fenómenos como el de la emancipación residencial y acceso a la vivienda (ECHAVES, 2018a).

Otra de las perspectivas es aquella que se centra en los usuarios, residentes, esto es, en la demanda residencial y sus comportamientos. Sin duda uno de los máximos exponentes es el sociólogo Kemeny (1992) y su función de "habitar", quién estudia la relación de los individuos con sus viviendas (hogares) y sus prácticas residenciales y espaciales.

Pero sin duda, muy sugerentes también son todas aquellas investigaciones que analizan la relación de la vivienda desde su producción u oferta con esta otra del comportamiento residencial de los hogares (LEAL, 2004 y 2018). Es decir, aquellos trabajos que tratan de ver los efectos que determinadas formas de producción tienen sobre las prácticas o comportamientos residenciales de los hogares en términos de acceso, usos, tenencia o localización (MARTínEZ, 2019; MódENES \& LÓPEZ, 2012).

social de las grandes ciudades españolas», financiado por el Ministerio de Economía, Industria y Competitividad. 
Partiendo de esta última perspectiva, el presente artículo analizará el comportamiento residencial de un colectivo muy concreto, los jóvenes (sus hogares), y atendiendo a varios fenómenos como son la emancipación residencial y acceso a la vivienda. Una vez fundado el hogar joven, se atenderá a una de las variables básicas (clave) en el análisis de los comportamientos residenciales: el régimen de tenencia, concretamente, el ascenso progresivo del alquiler. Recurriendo a fuentes estadísticas como la Encuesta de Población Activa (EPA), Observatorio de Emancipación, la Encuesta de Condiciones de Vida, el Ministerio de Fomento o los Presupuestos Generales del Estado (con datos en evolución y hasta 20182019), el elemento fundamental será entender el contexto en el que se produce el aumento de la demanda del alquiler por parte del colectivo juvenil y las condiciones (de acceso) de los hogares que viven bajo este régimen de tenencia. El cambio en el comportamiento residencial, derivado a su vez de un cambio demográfico y de los tipos de hogar (MóDENES \& LóPEZ, 2014), es real y se está produciendo (LEAL, 2018; MARTínEZ, 2018), pero siempre en un sistema residencial o de provisión muy característico (ECHAVES, 2018); para comprender lo primero será necesario prestar atención a la naturaleza y evolución de lo segundo.

Los jóvenes, como sujetos de la acción, "optan" por aquel régimen de tenencia que consideran más adecuado, pero quizá esta posibilidad de elección esté constreñida por una oferta residencial (regímenes de tenencia, precios) que moldea las "preferencias" $y$, en definitiva, que modela la demanda (JURADO, 2003 y 2006; ECHAVES, 2017a). Efectivamente, esta será una de las hipótesis que se defiende en el presente artículo.

El comportamiento residencial de los jóvenes en nuestro país ha tenido lugar en un sistema de provisión de vivienda (en adelante SPV) muy característico. España sigue ocupando un lugar muy concreto en las clasificaciones de los SPV en base al régimen de tenencia (ECHAVES, 2017b), con la propiedad como forma característica (con elevada bancarización y financiación de la compra a través de crédito). Lo que unido a bajas tasas de viviendas principales en alquiler y a costes elevados (predominio del mercado privado en detrimento del alquiler social), altos porcentajes de vivienda secundaria y el rol fundamental de la familia en la provisión de vivienda (ALLEN \& al., 2004; RoLAND, 2007), permitiría apoyar la tesis de la divergencia y la construcción de tipologías diferenciales específicas para los países del sur de Europa o mediterráneos (ECHAVES, 2018), con Estados o regímenes de bienestar muy característicos (FERRERA, 1995).
Este desequilibrio entre la propiedad y el alquiler no ha sido ajeno a procesos como el de la emancipación residencial y acceso a la vivienda por parte del colectivo juvenil. Históricamente en España el alquiler ha ofrecido escasas garantías, sin embargo, este régimen de tenencia puede representar la única salida existente para buena parte de los jóvenes. Por tanto, debemos partir de la hipótesis de que existe una proporción de la demanda de alquiler por parte de los jóvenes que puede no estar siendo satisfecha o serlo, pero de forma poco satisfactoria, debido a las condiciones que presenta el mercado; escasez de oferta y elevado precio, lo que finalmente genera elevados esfuerzos de acceso y retrasos en los procesos de emancipación.

En la última década, y como consecuencia del impacto del colapso económico y financiero sobre las condiciones de acceso, la crisis de la vivienda en nuestro país se ha agudizado, lo que a su vez ha tenido efectos en los comportamientos residenciales de los hogares (MARTínEZ, 2018). Uno de los cambios más significativos tiene que ver con el mercado de la propiedad y su deman$\mathrm{da}$, fuertemente retraída en beneficio del alquiler; un alquiler, no obstante, poco "atractivo", escasamente desarrollado y que tradicionalmente ha estado destinado a grupos poblacionales desfavorecidos (ARBACI, 2008). En un contexto de fuerte paro, de aumento de la precariedad laboral y devaluación salarial, la única opción residencial para muchos hogares demandantes ha sido la vivienda en alquiler, especialmente para los hogares jóvenes, con características laborales específicas y situados en una fase del ciclo del hogar muy concreta. Así, el principal objetivo del presente artículo será el de analizar las condiciones de acceso a la vivienda para este colectivo, partiendo de la hipótesis de que, a pesar del aumento observado de hogares jóvenes que residen en alquiler, el mercado del alquiler está provocando un deterioro de dichas condiciones (medidas a través del indicador de esfuerzo de acceso), generando así procesos de desigualdad residencial.

A pesar de las experiencias vividas en lo que llevamos de siglo $X X I$, en España la vivienda se sigue entendiendo como una mercancía, es un bien que se produce y que se consume, demandado y ofertado dentro de una lógica que conecta a individuos y hogares con los agentes encargados de proveer de este bien a la sociedad. La preponderancia de esta visión, el predominio de los elementos económicos y la función residual que se otorga a la vivienda social (PAREJA \& SÁNCHEZ, 2012), dan lugar a situaciones de monopolio y a un mercado especializado en el que quedan fuera ciertos colectivos, como es el 
de jóvenes, que para la lógica mercantil no forman parte de una demanda solvente (CORTÉs \& MARTínEZ, 2009). Se genera de esta manera una crisis para los jóvenes en el acceso a la vivienda, que para el caso del alquiler se traducirá en esfuerzos excesivos. Pero es una crisis nada novedosa, pues la mayor vulnerabilidad residencial de los jóvenes españoles puede entenderse como endémica a nuestro SPV.

España ocupa un lugar característico en las tipologías de SPV de nuestro entorno europeo. Ahora bien, esta diversidad no solo es aplicable y constatable entre países. Quizá sea posible establecer rasgos diferenciales y matices a una escala territorial menor, como por ejemplo, entre regiones de un mismo país (MÉNDEZ, ABAD \& ECHAVES, 2015). Efectivamente en España, aunque las Comunidades Autónomas participan del modelo general del país en el que se inscriben, las diferencias entre dichas comunidades son palpables. Una diversidad que implicará identificar divergencias asociadas a las características de los regímenes de provisión en cada una de las comunidades españolas (ECHAVES \& NAVARRO, 2018) y enmarcar la heterogeneidad como elemento inherente a un entorno homogéneo (ECHAVES \& ECHAVES, 2018). La diferenciación territorial de dichos regímenes que implica esta hipótesis impacta directamente sobre la manera particular en el que se articula la promoción de vivienda en cada una de las regiones, medida ésta a través de sus elementos económicos, esfuerzos de acceso al mercado del alquiler, y de los elementos políticos, mediante una propuesta de indicadores específicos.

Esto lleva a la presunción de que se asiste a sistemas de provisión más o menos favorables al proceso de emancipación residencial y de condiciones de acceso diferenciales (mejores y peores) según Comunidades Autónomas.

\section{El comportamiento residencial de los jóvenes: emancipación, régimen de tenencia y esfuerzos de acceso}

La emancipación residencial es un proceso mediado por una serie de comportamientos residenciales, pues tiene que ver no solo con el momento en el que se abandona (de manera definitiva o no) el hogar familiar y se forma uno propio en una vivienda independiente, sino, además, y una vez

\footnotetext{
2 La EPA define persona referencia del hogar aquella de designa el entrevistado como persona principal; anteriormente denominado sustentador principal. El resto de personas
}

fundado el nuevo hogar, está relacionado con las características de los hogares y viviendas de los jóvenes y las condiciones de acceso a las mismas. De esta forma, existirán distintas formas de medir este proceso atendiendo a los diversos comportamientos residenciales que existen en torno a él.

Aun entendiendo que los comportamientos residenciales de individuos y hogares hay que contextualizarlos en dinámicas y trayectorias más amplias de menor linealidad (o no-linealidad), mayor complejidad y desestandarización (Furlong, CARTMEl \& BiggarT, 2006), el presente artículo sigue una lógica secuencial que va desde el momento en el que los jóvenes se emancipan y forman hogares (su intensidad) hasta la forma en que lo hacen (régimen de tenencia) y las condiciones de acceso a la vivienda (esfuerzos). Así, los primeros indicadores que se utilizarán como aproximación al comportamiento residencial de los jóvenes son, a partir de la Encuesta de Población Activa (EPA), la tasa de emancipación de 16 a 34 años (o proporción de jóvenes que son clasificados como persona de referencia, cónyuge/pareja o persona no emparentada sobre el total de jóvenes de esa misma edad) $)^{2}$ y la tasa de principalidad (\% de hogares jóvenes). Estas tasas no nos permiten determinar la edad a la que se produce la emancipación y la posterior formación de hogares jóvenes, pero en cambio sí observar la frecuencia (mayor o menor) del fenómeno.

Numerosas investigaciones en nuestro país han confirmado el cambio de tendencia que se produce a comienzos del siglo XXI de disminución de jóvenes dependientes de los padres (LÓPEZ, 2008) y aumento de formación de los hogares; una realidad que no deja de ratificarse a pesar de la realidad económica (MORENO \& al., 2012) y del efecto que las crisis de empleo tienen sobre los fenómenos que aquí se están analizando.

Sea como fuere, y al igual que con crisis anteriores (REQUENA, 2002), la de 2008 supuso una disminución de las tasas de emancipación y de las tasas de principalidad en torno a 3 o 4 puntos porcentuales que durará hasta 2012 (ECHAVES 2018), momento a partir del cual se produce un ligero aumento de ambas tasas, para volver luego a disminuir desde 2014 hasta situarse en 2019 en un $44,7 \%$ en el caso de la tasa de emancipación (para el conjunto de jóvenes de 16 a 34 años), y en un $24,5 \%$ para el caso de la tasa de principalidad (ver FIG. 1).

convivientes en el hogar se definen en relación con ella: cónyuge/pareja, hijos, otros parientes, personas no emparentadas, etcétera. 


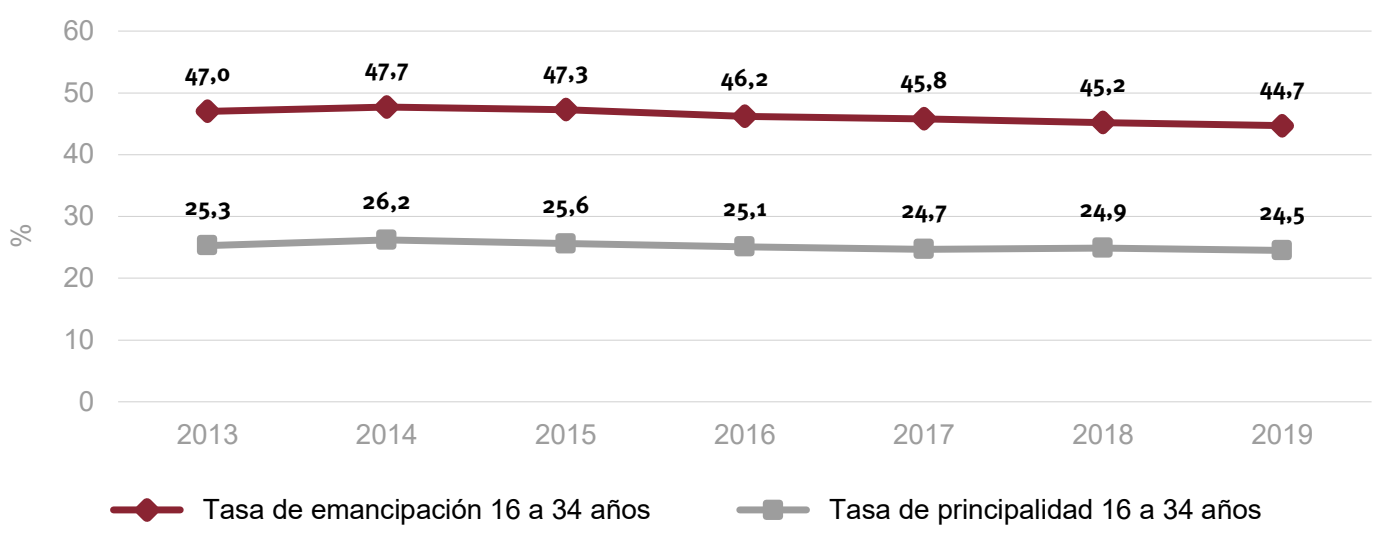

FIG. 1/ Evolución tasa de emancipación y tasa de principalidad de los hogares jóvenes de 16 a 34 años. España, 2013-2019.

Fuente: elaboración propia a partir de la ENCUESTA DE POBLACIÓN ACTIVA (INE), media de los trimestres.

Al margen del efecto evidente de las coyunturas económicas en la emancipación y formación de hogares por parte de los jóvenes, otros trabajos se han centrado en analizar los atributos que, cómo características y rasgos individuales, hacen variar la intensidad de las tasas. Por un lado, variables demográficas como el sexo, la edad, nacionalidad y estado civil guardan una estrecha relación con el estado (e intensidad) de la emancipación. De esta forma, está más que constatado que a mayor edad, si se es mujer, si se es extranjero y si se está casado, la tasa o porcentaje de emancipados es mayor (CACHón, 2004; VinUeSA, 2008; Stone \& al., 2010; EchaVes, 2017b), con una mayor frecuencia de formación de hogares (MIRET, 2010). Otros atributos de carácter socioeconómico, como la formación/cualificación y situación laboral de los jóvenes, también se muestran relevantes. En España, varias investigaciones han constatado que los jóvenes españoles con estudios universitarios tienden a retrasar el momento de la salida de la casa de los padres (JURADO, 1997; GAVIRIA, 2007; LÓPEZ, 2008), lo que a su vez acaba retrasando la formación del hogar propio. Una formación y cualificación que será clave para el posterior acceso a un puesto de trabajo por el que se obtendrá una remuneración económica, y que podría significar la obtención de la tan deseada independencia económica. Así, la relevancia de poseer un trabajo en condiciones dignas en los procesos de emancipación residencial es clave a la hora de emprender la transición a la vida adulta; es un aspecto fundamental en la configuración de las expectativas de los jóvenes y sus perspectivas de constitución de un nuevo hogar (MORENO \& al., 2012). Por último, trabajos recientes aplicadas al ámbito nacional han constatado la relevancia de variables que hacen referencia al estatus o posición de los individuos en la estructura social, si ésta se analiza mediante la condición socioeconómica (ECHAVES, 2017b y 2018). Concretamente se ha encontrado una relación positiva entre la emancipación y la condición socioeconómica, esto es, a mayor posición socioeconómica, mayor proporción de emancipados.

Ahora bien, más allá de la importancia de estos atributos o características individuales de los propios jóvenes, ¿qué factores contextuales nos pueden ayudar a entender la naturaleza de la emancipación y de los comportamientos residenciales de este colectivo? Como se verá más adelante, uno de esos factores es el SPV, analizado a través de las divergencias regionales que en nuestro país existen.

Avanzando ahora en los comportamientos residenciales y una vez que se produce la emancipación, los jóvenes forman un hogar propio en una vivienda independiente, siendo el régimen de tenencia una de las características más relevantes. En España, y a partir de 2008, el aumento del alquiler (\% de hogares que lo demandan) surge "como consecuencia directa del fatal desenlace que supuso el boom inmobiliario basado en la compra de vivienda" (MARTíNEZ, 2018:114). Así, en la última década se ha asistido a un crecimiento importante de la población que reside en sus viviendas en alquiler; para el conjunto de hogares, pero especialmente en los hogares jóvenes (ECHAVES, 2018). La mayor proporción de hogares jóvenes residiendo en alquiler es una realidad más allá de las coyunturas económicas, y esto es lógico si tenemos en cuenta que esta forma de apropiación de la vivienda es más adecuada para un colectivo que inicia su andadura en el ciclo del hogar, más tendente a la movilidad 
e instaurado en mayor medida en la precariedad laboral. No obstante, el alquiler en la actualidad puede representar (o ha representado) la única opción posible para el colectivo juvenil, por lo que la pregunta fundamental es ¿bajo qué condiciones se accede (se ha accedido) a este régimen de tenencia?

Siguiendo los datos que proporciona la Encuesta de Condiciones de Vida (ECV) elaborada por el INE, en el año 2015 el porcentaje de hogares jóvenes (16 a 34 años) en España que residían en alquiler ascendía al $46,7 \%$, un porcentaje que va aumentando progresivamente en 2016 (49,3\%), en $2017(51,1 \%)$, hasta situarse en 2018 en torno al $51 \%$. En paralelo, el peso relativo de los hogares jóvenes que habitan sus viviendas en propiedad disminuye, desde el $43,6 \%$ de los hogares en 2015 hasta el 38,7\% en 2018.

Este cambio en el comportamiento residencial de los hogares jóvenes (aumento del alquiler en términos relativos) es consecuencia de varios aspectos interrelacionados entre sí y consecutivos en el tiempo. Por una parte, la desconfianza hacia la compra de vivienda como efecto de situaciones residenciales dramáticas vividas por aquellos hogares que no pudiendo hacer frente al pago de la hipoteca, se vieron obligados a abandonar sus casas y, además, hacerse cargo de la deuda restante. Así, y en los años posteriores al estallido de la crisis de 2008, el alquiler (su demanda) se alza como una tenencia que no suponía la asunción de riesgos ni compromisos a largo plazo, a la vez que permitía el desarrollo de ciertas estrategias residenciales ante coyunturas económicas adversas (MARTíNEZ, 2018). En paralelo, el acceso a la compra se tornará más complicado ya que, y al margen de la bajada generalizada de los precios de la vivienda y de los intereses hipotecarios (RodRíGUEZ, 2017), la financiación será escasa, lo que unido al endurecimiento de las condiciones para la concesión de la hipoteca y la supresión de la desgravación fiscal por compra habitual de vivienda en 2013, provocarán que los hogares opten por el alquiler en mayor medida.

Por último, y no menos importante, la demanda del alquiler se ha visto reforzada como consecuencia del efecto que la inestabilidad laboral, la precariedad y la devaluación salarial tienen en el acceso a la vivienda; una inestabilidad y precariedad laboral mucho más presente en el colectivo juvenil (ECHAVES \& ECHAVES, 2017). De esta forma, y aunque muchos jóvenes querrían acceder a una vivienda en propiedad, se ven empujados al alquiler como la única alternativa habitacional posible. Pero como se verá a continuación, esta forma de apropiación de la vivienda no está exenta de problemas. Retomando la pregunta que se ha formulado más arriba, ¿bajo qué condiciones acceden los hogares jóvenes al alquiler en nuestro país? La forma de analizar estas condiciones (por otra parte, se trata también de un comportamiento residencial) es a través del indicador de esfuerzo de acceso.

El esfuerzo de acceso a la vivienda es un elemento básico para valorar el problema de la población joven y la vivienda, ya que dicho esfuerzo está relacionando dos aspectos (el precio de la vivienda y el poder adquisitivo o renta de individuos y hogares) que quizá constituyan los

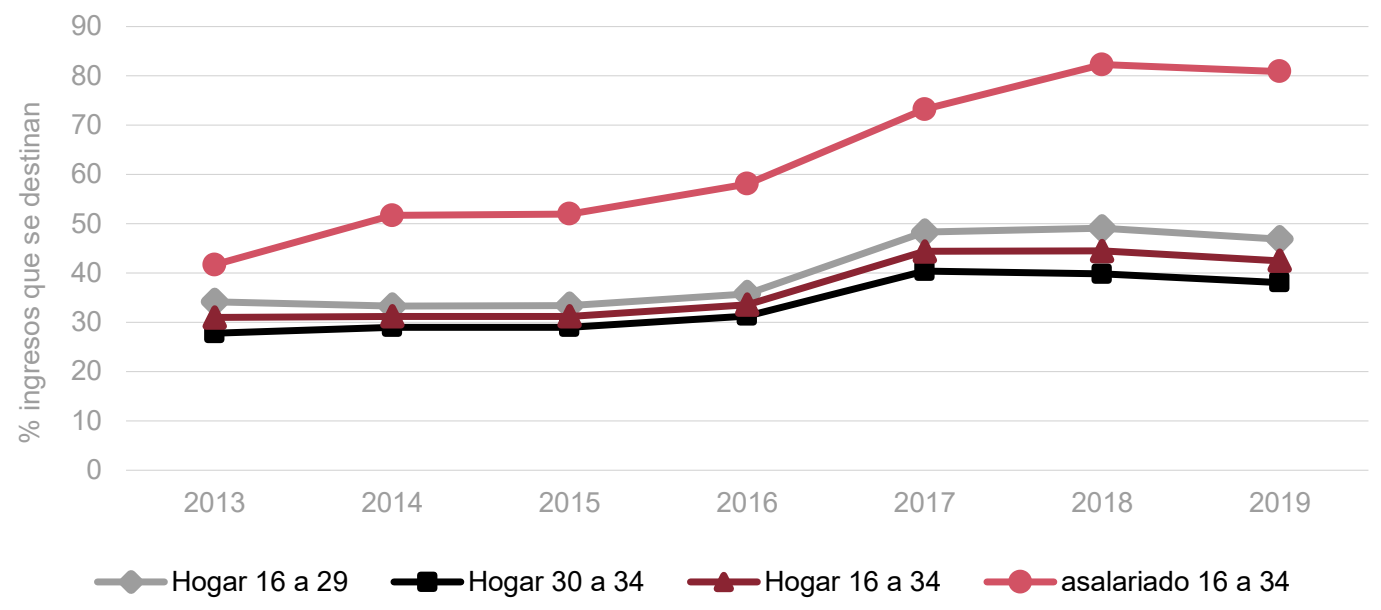

FIG. 2/ Evolución del Coste de acceso en alquiler para hogares jóvenes según grupos de edad y para joven asalariado de 16 a 34. España, 2013-2019 (\% de ingresos del hogar que se destina al pago de la renta mensual).

Fuente: elaboración propia a partir del OBSERVATORIO DE EMANCIPACIÓN, CONSEJO DE LA JUVENTUD EN ESPAÑA. 
principales escollos que están obstaculizando en nuestro país uno de los hitos más emblemáticos y visibles de la transición a la vida adulta, como es el abandono del hogar de los padres para trasladarse a una vivienda propia y formar un hogar. Es un indicador residencial que podríamos calificar de híbrido, ya que incorpora elementos de la demanda, como la edad y el poder adquisitivo de individuos y hogares, y aspectos claramente relacionados con la oferta: el precio que la vivienda alcanza en el mercado o el régimen de tenencia de las viviendas principales. Para el caso del esfuerzo de acceso al alquiler, y tomando como colectivo los hogares (jóvenes), su resultado se expresa en términos relativos y se interpreta como el porcentaje de los ingresos del hogar que se destinan a la renta mensual.

Atendiendo ahora a la FIG. 2, y según el Observatorio de Emancipación en España, el esfuerzo de acceso al alquiler, e independientemente de su evolución, varía según la edad del hogar joven. De esta manera, a menor edad (16 a 29 años) mayor esfuerzo y a la inversa, mayor edad (30 a 34 años) implica menor esfuerzo de acceso, algo lógico si presuponemos que con los años los individuos aumentan sus ingresos, la mayoría de las veces procedentes de las rentas del trabajo, y sus trayectorias (laborales) se tornan menos inseguras y menos precarias. Al margen de este hecho, y si tomamos en evolución al conjunto de hogares jóvenes (16 a 34 años), la FIG. 2 muestra que el esfuerzo de acceso al alquiler entre 2013 y 2015 se sitúa en torno al $31 \%$ (\% de ingresos del hogar dedicado al pago de la renta mensual), un dato que se encuentra alrededor del máximo tolerable recomendado (RODRÍGUEZ, 2010) y que se debe, fundamentalmente, a unas rentas del alquiler que se mantienen estables y que crecen interanualmente en torno al 2\% (ver FIG. 3).

La situación, no obstante, cambia partir de 2016. Siendo el esfuerzo de acceso al alquiler para el conjunto de hogares jóvenes en este año del $33,6 \%$, va aumentando progresivamente hasta situarse en 2017 en un $44,4 \%$ y un $44,5 \%$ para el año 2018. Además, este esfuerzo de acceso aumenta considerablemente si tomamos como unidad de análisis no los hogares, sino a un joven asalariado de forma individual. Según datos del Observatorio de Emancipación en España (Consejo de la Juventud) el esfuerzo de acceso en alquiler para un joven asalariado se situaba en 2018 en un $82,3 \%$, casi el triple del máximo tolerable recomendado (ver FIG. 2) ${ }^{3}$.

La evolución del esfuerzo de acceso al alquiler guarda relación, cómo no, con la evolución de los precios del alquiler y de los salarios de los jóvenes. Tal y como muestra la figura 3 , la renta del alquiler se incrementa interanualmente de manera progresiva desde el ejercicio 2014-2015 hasta alcanzar valores máximos del $23,3 \%$ en 2016-2017. En 2017-2018 el incremento interanual se apacigua, aunque sigue siendo elevado $(12,4 \%)$ y continúa

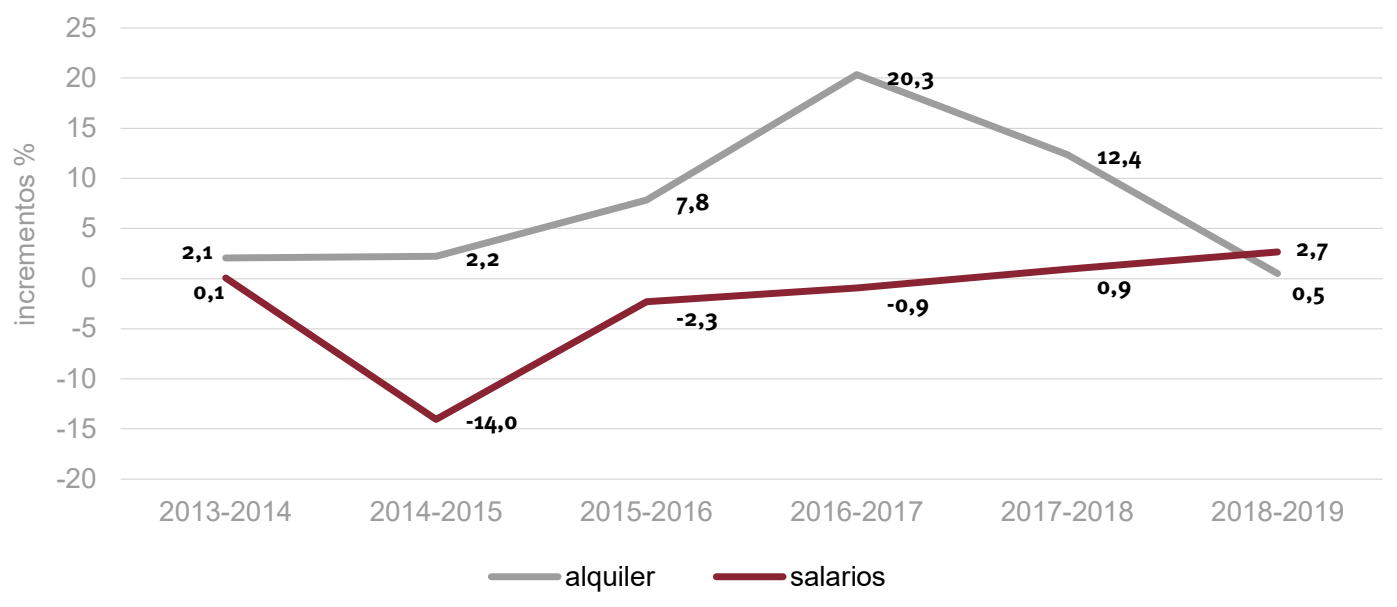

FIG. 3 / Incrementos relativos anuales (\%) renta del alquiler y de los salarios de los jóvenes (16 a 34 años) en España, 2013-2019.

Fuente: elaboración propia a partir del OBSERVATORIO DE EMANCIPACIÓN, CONSEJO DE LA JUVENTUD EN ESPAÑA. 3 Si la unidad de análisis es un joven con ingresos ordinarios
(que es la suma de los que trabajan, y tienen un salario, y
los que no trabajan, y de estos últimos tanto los que reciben prestación por desempleo como aquellos que no reciben ninguna ayuda) el esfuerzo se eleva en 2018 hasta la dramática cifra de un $148,5 \%$. 
descendiendo hasta situarse en 2018-2019 en $0,5 \%$. Más allá de este último dato, la serie siempre muestra subidas (mayores o menores) del precio de la vivienda en alquiler a la par que un decrecimiento de los salarios de los jóvenes ${ }^{4}$.

De esta forma, subida de los precios y bajos salarios explican el difícil contexto actual de acceso a la vivienda (en alquiler) por parte del colectivo juvenil en España. Una realidad, además, que se reproduce en todas las regiones de nuestro país, aunque con distinto ritmo, lo que acabará dibujando diferencias en los comportamientos residenciales según Comunidades Autónomas. Éstas últimas, a pesar de inscribirse en el modelo general español, muestran divergencias en sus SPV; divergencias que podrían ser explicativas, a su vez y como se verá, de las diferencias en los comportamientos residenciales según regiones.

\section{Las divergencias territoriales en el comportamiento residencial de los jóvenes: análisis por Comunidades Autónomas}

Desde 2013 y hasta el presente, tiene lugar en el conjunto del país un descenso progresivo de las tasas de emancipación (recordar FIG. 1), un descenso que, además, y según la Encuesta de
Población Activa, se produce en todas y cada una de las Comunidades Autónomas españolas. Independientemente de la evolución por regiones, y si tomamos un año de referencia (2018), la intensidad del fenómeno (lejos de ser homogéneo en todo el territorio) muestra una clara segmentación. Efectivamente, y si atendemos a la FIG. 4, se observan claras diferencias; existen CC. AA. cuyas tasas de emancipación se encuentran en torno a la media nacional, otras regiones en las que el porcentaje de emancipados está por debajo y, finalmente, regiones en donde la tasa de emancipación se sitúa claramente por encima del valor para el conjunto del país.

Al margen de atributos o características individuales de los propios jóvenes (descritas con anterioridad) y sus efectos en el estado e intensidad de la emancipación, ¿qué factores contextuales nos pueden ayudar a explicar estas variaciones regionales? En una primera aproximación, tomando las tasas de paro juvenil en cada Comunidad Autónoma (que bien pueden servir como indicador de un elemento estructural como es el mercado laboral) y relacionándolas con las tasas de emancipación respectivas de cada región, se observa una asociación clara. Así, las Comunidades Autónomas con mayores tasas de paro presentan menores tasas de emancipación, mientras que menores tasas de paro implican tasas de emancipación más elevadas (FIG. 5).

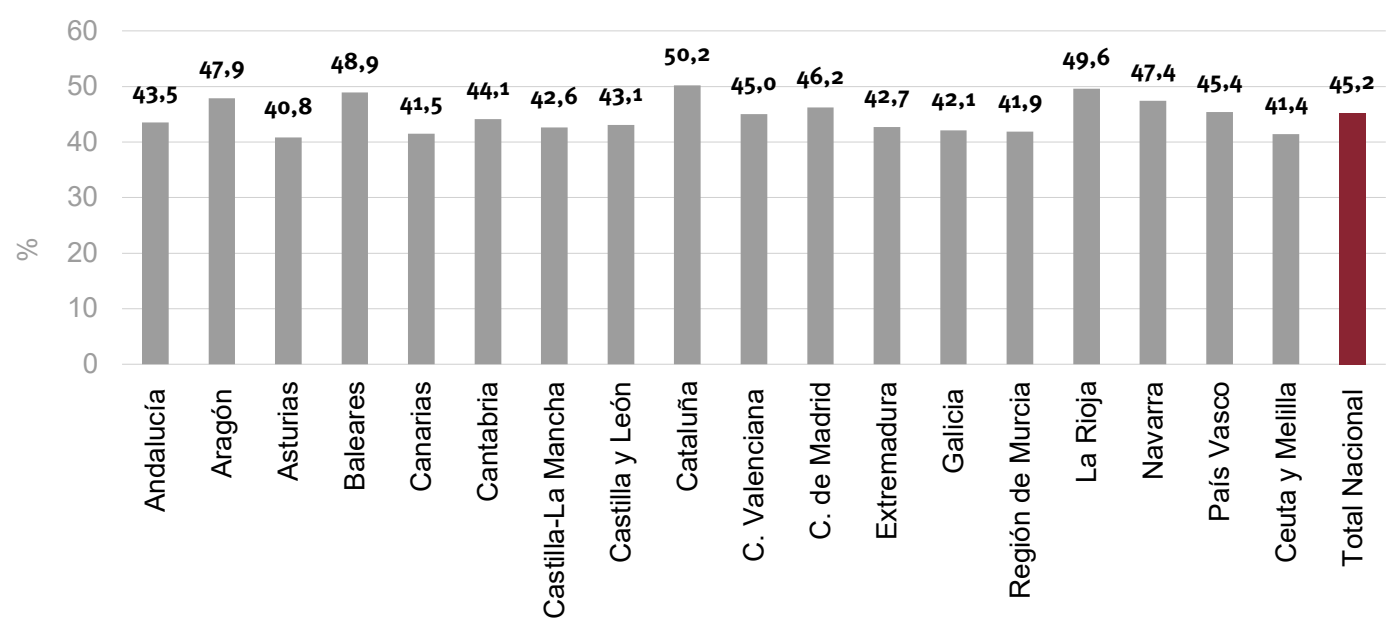

FIG. 4/ Tasa de emancipación de los jóvenes de 16 a 34 años por CC. AA. España, 2018.

Fuente: elaboración propia a partir de la ENCUESTA DE PoBLACIÓN ACTIVA (INE). Datos al II trimestre.

\footnotetext{
${ }^{4}$ Según datos del Observatorio de Emancipación (Consejo de la Juventud) y de la Encuesta de Estructura salarial (INE), el precio medio del alquiler en España para 2013 se situaba en 539,2 (euros/mes), alcanzando los 880 (euros/mes) en
}

2019. En paralelo al encarecimiento de la vivienda, los salarios de los jóvenes (media para un joven de 16 a 34 años) descienden desde los $15.236,5$ (euros netos anuales) en 2013 hasta los 13.426,5 en 2019. 


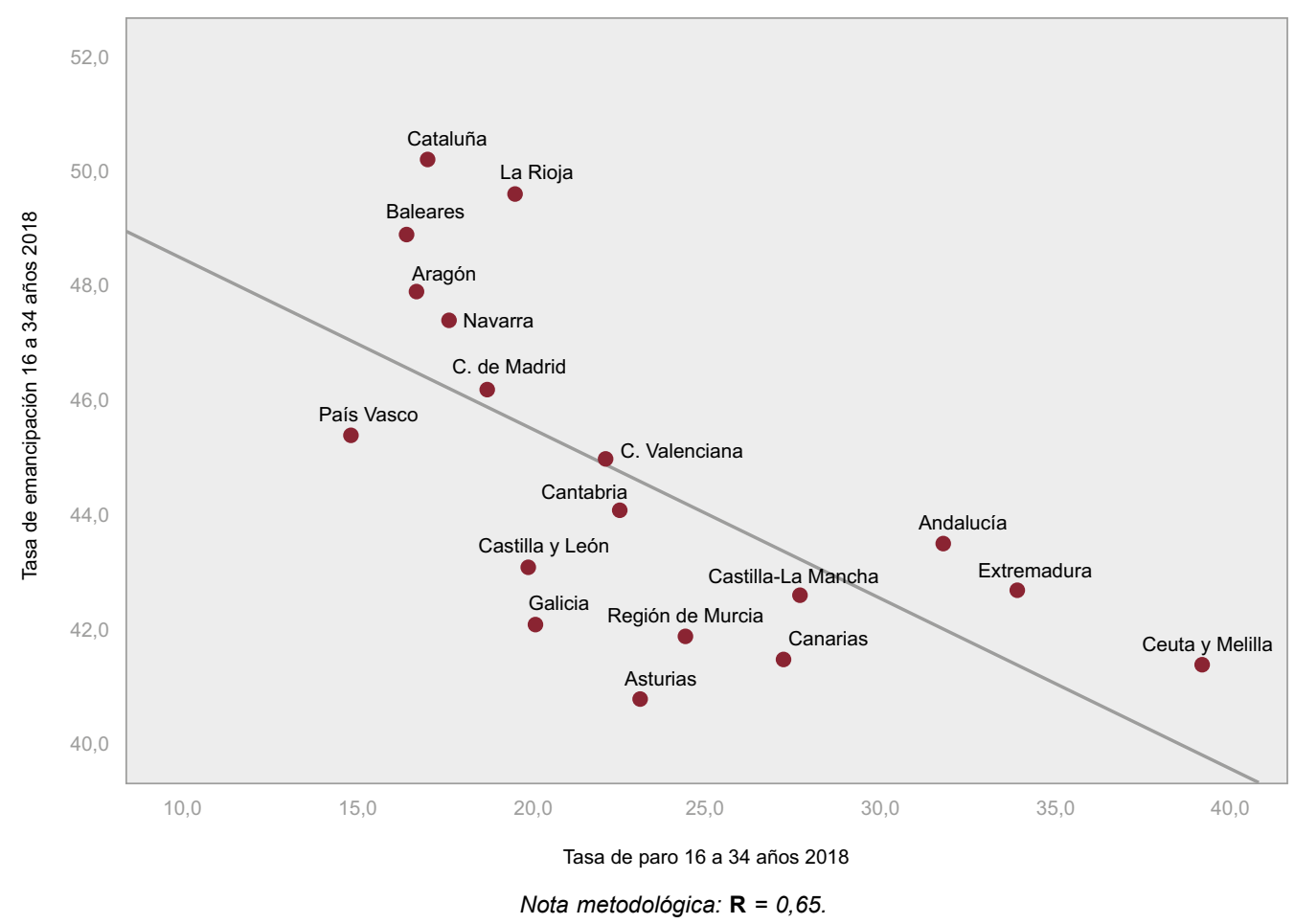

FIG. 5/ Dispersión simple tasas de emancipación y tasas de paro (16 a 34 años) por CC. AA. España, 2018.

Fuente: elaboración propia a partir de la ENCUESTA DE POBLACIÓN ACTIVA (INE), datos al II Trimestre.

Pero más allá de esta evidencia empírica, del efecto contextual del paro en los procesos de emancipación (JURADO, 1997; MIRET, 2005; ECHAVES, 2017b), el interés del presente artículo radica (como se verá más adelante) en relacionar indicadores del SPV, también como elementos contextuales, con la emancipación y los comportamientos residenciales a través de las divergencias territoriales.

El comportamiento residencial de los hogares, medido a través del alquiler, se muestra también dispar en las distintas regiones, tal y como puede observarse en la primera columna de la FIG. 6 , desde el 36,9\% en Andalucía hasta el 62,7\% en la Comunidad de Madrid. Acompañando al dato del \% de hogares jóvenes que residen el alquiler, se muestran los precios de la vivienda tanto para el régimen de tenencia en propiedad como en alquiler (muy dispares en el territorio), así como un indicador elaborado que hace referencia al diferencial del precio entre ambos regímenes de tenencia. Ahora bien, ¿es posible relacionar esta característica tan esencial de la oferta de vivienda, como es el precio que alcanza la vivienda en el mercado libre, con el régimen de tenencia "escogido" por los hogares jóvenes? Un dato este último que se puede considerar como indicador de la demanda residencial y muestra sus comportamientos. En la elección del régimen de tenencia pueden ser importantes las preferencias de los jóvenes y también características demográficas y socioeconómicas individuales, como la edad, la forma de convivencia y el poder adquisitivo, pero ¿por qué no pensar que en la elección de la forma de tenencia también puede influir el precio que la propiedad y el alquiler alcanzan en el mercado? Este interrogante lleva al planteamiento de la siguiente hipótesis: allí (Comunidad Autónoma) donde la diferencia entre el precio de la propiedad y el precio del alquiler es mayor, el porcentaje de hogares jóvenes residiendo en alquiler aumentará. En esta hipótesis se asume pues cierta racionalidad económica en los jóvenes, de tal manera que el alquiler será atractivo y una opción a tener en cuenta si el precio es competitivo en relación a la propiedad.

Para contrastar esta hipótesis se ha elaborado un indicador con la diferencia en cada comunidad entre el precio de la propiedad y el precio del alquiler (última columna FIG. 6), de tal manera que si al precio de la propiedad se le resta el precio del alquiler se obtiene un diferencial que es el que va a actuar como variable que podría explicar la proporción de hogares jóvenes residiendo 
en alquiler en las distintas regiones españolas. La información que muestra la FIG. 6 nos obliga a ser cautos, dado que existen regiones, como la vasca, la cántabra o la asturiana, en la que la regla no se cumple. Aun así, es cierto también que en otras muchas la relación entre el indicador de la diferencia de los precios y el \% de hogares jóvenes en alquiler es la que se esperaba. En la Comunidad de Madrid, Cataluña o Baleares (al ser el diferencial del precio mayor) la proporción de hogares que optan por el alquiler aumenta. Por el contrario, en comunidades como Extremadura, Castilla-La Mancha, Región de Murcia, C. Valenciana o La Rioja, la diferencia entre el precio de la propiedad y el precio del alquiler es mucho menor, lo que se traduce en tasas menores de hogares jóvenes residiendo en alquiler.

Sin ánimo de hacer generalizaciones y como aproximación, pues son datos agregados, la FIG. 7 proporciona una comprobación más visual de la relación entre el indicador de demanda y el indicador de la oferta en el año 2018 (y con una correlación de Pearson- $R$ - de 0,49). Así, se observa una tendencia positiva, pues a medida que aumenta el diferencial del precio entre la propiedad y el alquiler, aumenta el porcentaje de hogares jóvenes que habitan sus viviendas en alquiler.

De esta forma, un indicador de demanda residencial, como es el porcentaje de hogares jóvenes en alquiler puede estar influido por una característica de la oferta: los precios (concretamente diferencial de los precios) que en cada una de las regiones presentan los regímenes de tenencia. Como primer acercamiento al fenómeno, se puede afirmar que la oferta residencial en un momento y un lugar concreto no es sólo resultado del crecimiento y de las características de la demanda, sino que también es el resultado de los propios mecanismos del mercado y de ciertas normativas que estarían generando un stock de vivienda, que como bien que se produce (y consume), moldea a su vez la demanda (JURADo, 2003; ECHAVES, 2017a).

Es momento ahora de seguir caracterizando el SPV de nuestro país. Un sistema que más allá de sus aspectos económicos (esfuerzos de acceso al mercado-libre-), se caracteriza por unos elementos políticos que se cimentan a partir de diferentes factores que tienen como objetivo estructurar y organizar la acción pública sobre dicho

\begin{tabular}{|c|c|c|c|c|}
\hline CC. AA & $\begin{array}{c}\text { \% hogares } \\
16 \text { a } 34 \text { en } \\
\text { alquiler }\end{array}$ & $\begin{array}{l}\text { Precio vivienda } \\
\text { libre en propiedad } \\
\left(\text { euros } / \mathrm{m}^{2}\right)\end{array}$ & $\begin{array}{c}\text { precio vivienda } \\
\text { libre en alquiler } \\
\text { (euros/mes) }\end{array}$ & $\begin{array}{l}\text { Diferencial precio } \\
\text { propiedad - alquiler } \\
\text { (en euros) }\end{array}$ \\
\hline Andalucía & 36,9 & 1234,2 & 644,4 & 589,8 \\
\hline Aragón & 49,2 & 1178,4 & 515,1 & 663,3 \\
\hline Asturias & 43,0 & 1291,9 & 476,3 & 815,6 \\
\hline Baleares & 53,7 & 2178,3 & 1091,3 & 1087 \\
\hline Canarias & 53,6 & 1423,9 & 695,7 & 728,2 \\
\hline Cantabria & 40,9 & 1472,8 & 550,1 & 922,7 \\
\hline Castilla-La Mancha & 46,2 & 874,2 & 480,8 & 393,4 \\
\hline Castilla y León & 48,7 & 1044,7 & 482,4 & 562,3 \\
\hline Cataluña & 60,7 & 1982,0 & 1019,9 & 962,1 \\
\hline C. Valenciana & 43,1 & 1151,1 & 610,4 & 540,7 \\
\hline C. de Madrid & 62,7 & 2330,1 & 1101,6 & 1228,5 \\
\hline Extremadura & 38,3 & 860,3 & 355,5 & 504,8 \\
\hline Galicia & 41,1 & 1192,0 & 465,6 & 726,4 \\
\hline Región de Murcia & 41,0 & 979,0 & 527,4 & 451,6 \\
\hline La Rioja & 42,6 & 1074,9 & 418,9 & 656 \\
\hline Navarra & 52,1 & 1344,9 & 610,9 & 734 \\
\hline País Vasco & 46,4 & 2376,9 & 863,0 & 1513,9 \\
\hline Ceuta y Melilla* & - & 1631,3 & - & - \\
\hline
\end{tabular}

${ }^{*}$ El dato no se puede elaborar o no es estadísticamente representativo.

FIG. 6/ Hogares jóvenes en alquiler (\%), precios de vivienda según régimen de tenencia y diferencial precio propiedad-alquiler. España, 2018. 


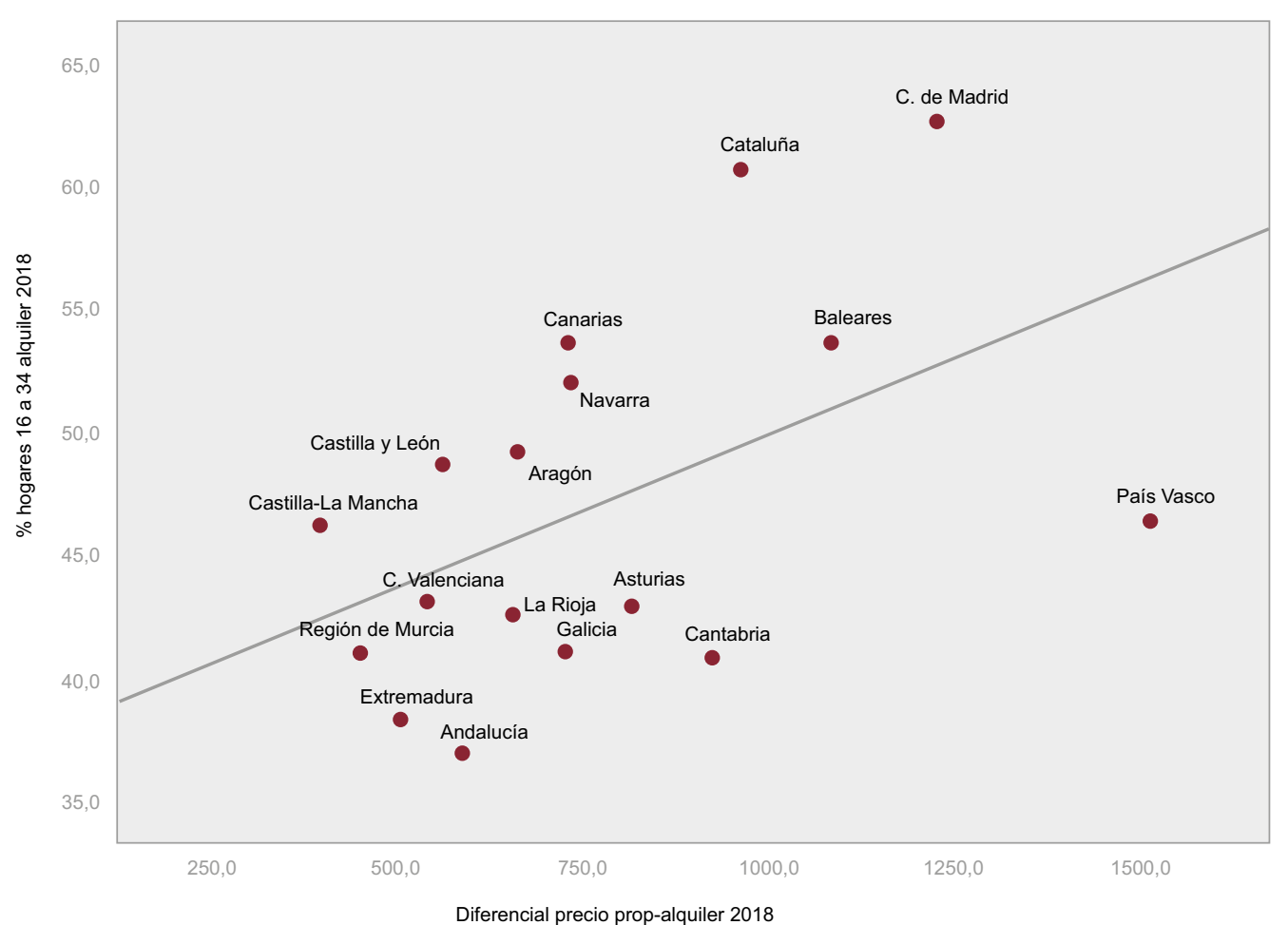

Nota metodológica: $\mathbf{R}=0,49$.

FIG. 7 / Dispersión simple \% de hogares jóvenes residiendo en alquiler (16 a 34 años) y diferencial precio propiedad-alquiler por CC. AA. España, 2018.

Fuente: elaboración propia a partir de la ECV (INE), Estadísticas del antiguo MINISTERIO DE FOMENTO Y VIVIENDA Y DEL OBSERVATORIO DE EMANCIPACIÓN (CONSEJO DE LA JUVENTUD EN ESPAÑA).

sistema (CORTÉS, 1995; ECHAVES, 2018), y de esta manera regular los procesos de provisión. El resultado de todo ello sería la existencia de una política específica para vivienda.

\section{Indicadores del Sistema de Provisión de Vivienda en España, desde una perspectiva autonómica comparada, y su relación con la emancipación residencial}

La política de vivienda en nuestro país (como elemento del SPV) es más débil que la existente en otras latitudes del continente europeo y está subordinada a los mecanismos que establece el mercado (ECHAVES, 2018); posee una naturaleza que poco ha variado con el paso de los años, al menos en su forma de intervención (LEAL \& MARTíneZ, 2017). Aunque es cierto que en los últimos planes de vivienda se observa cierto cambio en la manera de entender la vivienda (Plan Estatal de Vivienda y Rehabilitación
2009-2012; Plan Estatal de Fomento del Alquiler de Viviendas, la Rehabilitación edificatoria, y la Regeneración y Renovación urbanas 2013-2016; Plan Estatal de Vivienda 2018-2021), se trata en términos generales de una política, la de vivienda, sin rupturas y continuista en su provisión y en los instrumentos utilizados: predomino de ayudas directas (primero a la oferta, después a la persona o demanda) e importancia de ayudas indirectas en forma de incentivos fiscales, esto es, una política tendente a transmisiones de dinero y no a prestación de servicios (GoNZÁLEZ, 2000; PAREJA \& SÁNCHEZ, 2012).

Además, esta política de vivienda no ha sido ajena (es causa) de la extensión desmedida de la propiedad como forma dominante de tenencia (NASARRE, 2017). Y la opción (mayoritaria) por la tenencia en propiedad está relacionada con el tipo de sistema o régimen de bienestar que los caracteriza, del sur de Europa (FERRERA, 1995 y 2010) o Estados de bienestar meridionales (FLAQUER, 2004). Aunque sea cierto que puedan existir en estas sociedades, como España, percepciones sociales generalizadas en torno a las 
virtudes de la propiedad como reflejo de una posición socioeconómica aventajada y como forma segura de inversión (GAVIRIA, 2007; PAREJA, 2010), trasmitida a través de una socialización estratégico-familiar, estas no son sino el reflejo de las características y recursos que se derivan de ciertos regímenes de desarrollo en donde se enmarcan políticas de vivienda determinadas. Nos encontraríamos, pues, ante sistemas (los de provisión de vivienda) que conforman, y a su vez son conformados, por los regímenes de bienestar en los que se hallan inmersos, y en España, su sistema de bienestar se correlaciona de forma clara con el predominio del régimen en propiedad y con las oportunidades de emancipación residencial juvenil (PATÓN, 2007).

Desde un punto de vista de la política, el alquiler social o a precio reducido (como indicador elaborado "viviendas protegidas en alquiler") representa una opción adecuada para impulsar institucionalmente las aspiraciones de los jóvenes de un proyecto residencial independiente y autónomo, pues a medida que se incrementan las ayudas dirigidas a esta forma de tenencia, los procesos de emancipación se pueden tornar rápidos y tempranos; realidad que contrasta claramente con los países del área mediterránea, como es el caso de España, en donde

“(...) el sistema de bienestar se corresponde con un determinado régimen de propiedad... con una emancipación juvenil muy tardía (y) la presencia del alquiler es mínima... viniendo a reforzar el marco contextual del retraso en la emancipación residencial de los jóvenes" (PATón, 2007: 540).

De esta forma, los recursos disponibles y las expectativas materiales (traducidos en políticas y medidas públicas de vivienda) podrían ser explicativos de fenómenos transicionales como el de la emancipación residencial. En este sentido, a continuación, se muestran datos sobre política de vivienda en España que, medida a través de una serie de indicadores, manifiestan la naturaleza de la actuación pública en nuestro país y reflejan (más allá de la especificidad de modelo español y su ubicación en las clasificaciones europeas) las disparidades que existen en cuanto al esfuerzo que cada Comunidad Autónoma efectúa en materia de vivienda.

En nuestro país la intervención pública en materia de vivienda debe entenderse en un contexto de transformación o paso de un modelo centralizado a otro descentralizado, que se inicia con

\footnotetext{
${ }^{5}$ Además de los indicadores sobre política de vivienda para así caracterizar el SPV español, se ha añadido una primera columna con el indicador de esfuerzo de los hogares jóvenes
}

la Constitución Española de 1978 y se afianza con la aprobación de los estatutos de autonomía de cada comunidad y la transferencia de competencias. Así, las Comunidades Autónomas tienen la capacidad de desarrollar, siguiendo ciertas directrices marcadas por los planes estatales, sus propias políticas de vivienda con cargo a sus presupuestos.

Una primera manera de distinguir tipologías es en base al gasto público que cada una de las regiones destina a vivienda. Así, como indicador de esfuerzo público para 2018, el gasto en vivienda (bruto, en millones de euros) se ha relacionado tanto con el total del gasto (\% respecto al total del gasto) como con la población que reside en cada de las autonomías (euros en vivienda per cápita), tal y como se observa en la FIG. $8^{5}$. Como muestran los datos, el gasto en vivienda no se distribuye de manera igualitaria en las distintas regiones; al contrario, existen comunidades donde el esfuerzo en vivienda es claramente mayor (medido como gasto público en vivienda respecto al total del gasto y gasto en vivienda euros por persona), $\mathrm{y}$ otras donde es menor.

En la tarea de clasificar a las Comunidades Autónomas en materia habitacional, a continuación, es necesario introducir otro mecanismo que en España ha sido fundamental para entender la forma de intervención sobre la vivienda: la Vivienda de Protección Oficial (CORTÉs, 1995; GoNZÁlEZ, 2000; ECHAVES, 2018).

Una política que adquiere protagonismo a partir del Real Decreto-Ley (del año 1978) 31/78 sobre Viviendas de Protección Oficial de categoría única, cuyo objetivo era racionalizar el régimen de categorías y normativas vigentes hasta ese momento, lo que supuso la descentralización de la promoción pública de vivienda de protección oficial (CORTÉs, 1995). A esta ley inicial le siguieron otras, pero casi siempre enmarcadas en los planes de vivienda: Plan Trienal (19811983); Plan Cuatrienal (1984-1987); RealesDecretos 1494/87 y 224/89; los Decretos 1968/91 y 1932/91, contextualizados en el Plan Estatal de Vivienda 1992-1995; y diversas modificaciones en los planes estatales de la década de los 2000 (2005-2008, 2009-2012 y 2013-2016) que han supuesto ciertos cambios en determinados aspectos de esta forma de intervención pública, especialmente en lo que al establecimiento de precios y superficies máximas se refiere, e ingresos mínimos y máximos de los hogares para

al mercado del alquiler, para así evidenciar condiciones de acceso al mercado, peores y mejores, según Comunidades Autónomas. 
acceder a las distintas tipologías de protección (promoción pública, promoción directa, régimen especial, régimen concertado, etc...).

Dicho esto, en las dos últimas columnas de la FIG. 8 se muestran datos en evolución (stock acumulado y por Comunidades Autónomas) de viviendas protegidas terminadas (2011-2018) respecto del total de viviendas terminadas (protegida + libre) en ese periodo (\%), y viviendas protegidas en alquiler (2005-2018) respecto al total de viviendas protegidas en ese periodo, también en términos porcentuales. Siendo ambos indicadores una aproximación del stock acumulado en la actualidad, que clasifican el SPV por regiones y que nos hablan de la forma de intervención de cada una de ellas en materia de vivienda, en este trabajo se considera sumamente relevante el último de ellos ("\% viviendas protegidas en alquiler respecto total viviendas protegidas 20052018"). Si partimos de la idea de que el alquiler (a un precio asumible) representaría para los jóvenes (recordemos) una forma de apropiación de la vivienda adecuada, en ocasiones única opción, para una determinada fase del ciclo del hogar, podemos entender este indicador como específico de oportunidades de acceso a la vivienda por parte de los jóvenes y, por tanto, de emancipación residencial. Además, se trata de un indicador clásico en la literatura científica europea (vivienda social-protegida-en alquiler) para diferenciar distintos regímenes de provisión de vivienda (BOELHOUWER \& VAN DER HEIJDEN 1994; HARLOE, 1995; KEMENY, 1995; HAFFNER \& al., 2009; HOEKSTRA, 2010; ECHAVES \& NAVARRO, 2018). Pero veamos a continuación qué relación puede establecerse entre las divergencias por Comunidades Autónomas en este indicador de vivienda (2005-2018) y las diferencias regionales referentes a la emancipación en 2018 (intensidad de las tasas).

Tal y como se observa en la FIG. 9, existe relación lineal con tendencia positiva $(R=0,47)$, lo que significa que a medida que aumenta el porcentaje de vivienda protegida en alquiler, se incrementa la tasa de emancipación. Con estos datos agregados, y como primera aproximación, las tasas de emancipación que existen en cada una de las regiones españolas se ven influidas positivamente por la mayor presencia de este tipo de alquiler protegido.

\begin{tabular}{|c|c|c|c|c|c|}
\hline CC. AA & $\begin{array}{l}\text { Coste de acceso al } \\
\text { mercado del } \\
\text { alquiler para hogar } \\
\text { joven, } 2018 \text { (\% de } \\
\text { ingresos } \\
\text { destinados) }\end{array}$ & $\begin{array}{l}\text { Gasto público } \\
\text { en Vivienda (\% } \\
\text { respecto al total } \\
\text { de gasto) } 2018\end{array}$ & $\begin{array}{l}\text { Gasto } \\
\text { público en } \\
\text { vivienda } \\
\text { (euros per } \\
\text { cápita) } \\
\mathbf{2 0 1 8}\end{array}$ & $\begin{array}{l}\text { \% Viviendas } \\
\text { protegidas } \\
\text { terminadas } \\
2011-2018(\% \\
\text { respecto del total } \\
\text { de viviendas } \\
\text { terminadas) }\end{array}$ & $\begin{array}{l}\% \text { viviendas } \\
\text { protegidas en } \\
\text { alquiler } \\
\text { respecto total } \\
\text { viviendas } \\
\text { protegidas } \\
2005-2018\end{array}$ \\
\hline Andalucía & 44,1 & 0,9 & 33,1 & 26,1 & 20,0 \\
\hline Aragón & 26,0 & 0,7 & 30,4 & 27,9 & 20,8 \\
\hline Asturias & 30,3 & 0,8 & 31,4 & 28,0 & 15,8 \\
\hline Baleares & 56,0 & 0,5 & 23,2 & 3,9 & 52,2 \\
\hline Canarias & 40,9 & 1,0 & 39,8 & 12,4 & 26,9 \\
\hline Cantabria & 32,3 & 0,9 & 40,9 & 21,8 & 8,4 \\
\hline Castilla y León & 29,6 & 0,6 & 26,4 & 13,8 & 9,1 \\
\hline Castilla La-Mancha & 28,1 & 0,6 & 24,6 & 18,6 & 1,8 \\
\hline Cataluña & 56,5 & 0,6 & 25,5 & 19,9 & 34,5 \\
\hline C. Valenciana & 40,8 & 0,5 & 19,8 & 15,3 & 21,7 \\
\hline Extremadura & 52,8 & 1,0 & 46,9 & 27,7 & 5,8 \\
\hline Galicia & 23,1 & 0,8 & 32,6 & 10,6 & 19,4 \\
\hline C. de Madrid & 28,0 & 1,5 & 50,2 & 48,6 & 22,0 \\
\hline Región de Murcia & 41,5 & 1,1 & 40,2 & 10,7 & 7,9 \\
\hline Navarra & 23,0 & 1,5 & 95,3 & 52,8 & 19,5 \\
\hline País Vasco & 27,9 & 1,2 & 61,4 & 37,9 & 16,3 \\
\hline La Rioja & 40,6 & 0,7 & 35,5 & 15,8 & 10,8 \\
\hline Ceuta y Melilla & - & 2,0 & 58,0 & 12,2 & 13,1 \\
\hline
\end{tabular}

FIG. 8/ Indicadores del Sistema de Provisión de Vivienda por CC. AA. España, 2005-2018.

Fuente: elaboración propia a partir del OBSERVATORIO DE EMANCIPACIÓN (CONSEJO DE LA JUVENTUD EN ESPAÑA); de la Liquidación de Presupuestos, SECRETARÍA DE ESTADO DE ADMINISTRACIONES PúBLICAS (MINISTERIO DE HACIENDA Y Administraciones Públicas) y Estadísticas de vivienda del antiguo Ministerio de Fomento. 
Sustantivamente, las FIGS. 8 y 9 nos hablan de algo sumamente relevante: que pueden existir distintos SPV a escala sub-nacional. Estos SPV se diferenciarían en base al esfuerzo público que cada Comunidad Autónoma lleva a cabo para poner a disposición de la ciudadanía, y del colectivo juvenil, vivienda en régimen de alquiler.

Como se ha dicho anteriormente, los jóvenes se encuentran en una fase del ciclo del hogar muy característica, siendo el alquiler un régimen de tenencia apropiado y en ocasiones única opción para esa etapa. Así pues, es obligación de las instituciones impulsarlo para facilitar así las aspiraciones juveniles de una vida habitacional autónoma e independiente; en definitiva, para facilitar la emancipación y el tránsito a la vida adulta.

\section{Conclusiones}

La crisis permanente que impide la satisfacción de las necesidades residenciales de los grupos sociales más vulnerables pone en el punto de mira la relevancia del SPV español como una causa fundamental que debe ser abordada de forma urgente.
Tal y como se demuestra en el presente artículo, existe una relación inequívoca entre las condiciones de emancipación de los jóvenes y las dinámicas que adopta un SPV sometido al libre mercado (y sus fluctuaciones) y sustentado en la promoción de la propiedad. De esta forma, al margen de la influencia que, sobre los comportamientos residenciales de los jóvenes, juegan los factores ligados a la demanda como puedan ser los demográficos, socioeconómicos o individuales; se observa cómo el encarecimiento progresivo de un mercado de alquiler escaso, deteriorado y fuertemente especulativo ha derivado en un empeoramiento de las condiciones residenciales de los jóvenes, agravándose así las ya complicadas estrategias que deben poner en marcha para lograr una salida habitacional y vital. Así pues, si bien la crisis del 2008 supuso el renacimiento de un mercado de alquiler que se alzaba, aún más, como la única opción residencial para los jóvenes, la subida de precios impuesta por la lógica del mercado ha borrado en buena medida esta posibilidad. De esta forma, si bien el porcentaje de hogares jóvenes residiendo en alquiler ha crecido, también lo ha hecho el esfuerzo que deben realizar para acceder a una vivienda, presionando así hacia una caída progresiva en

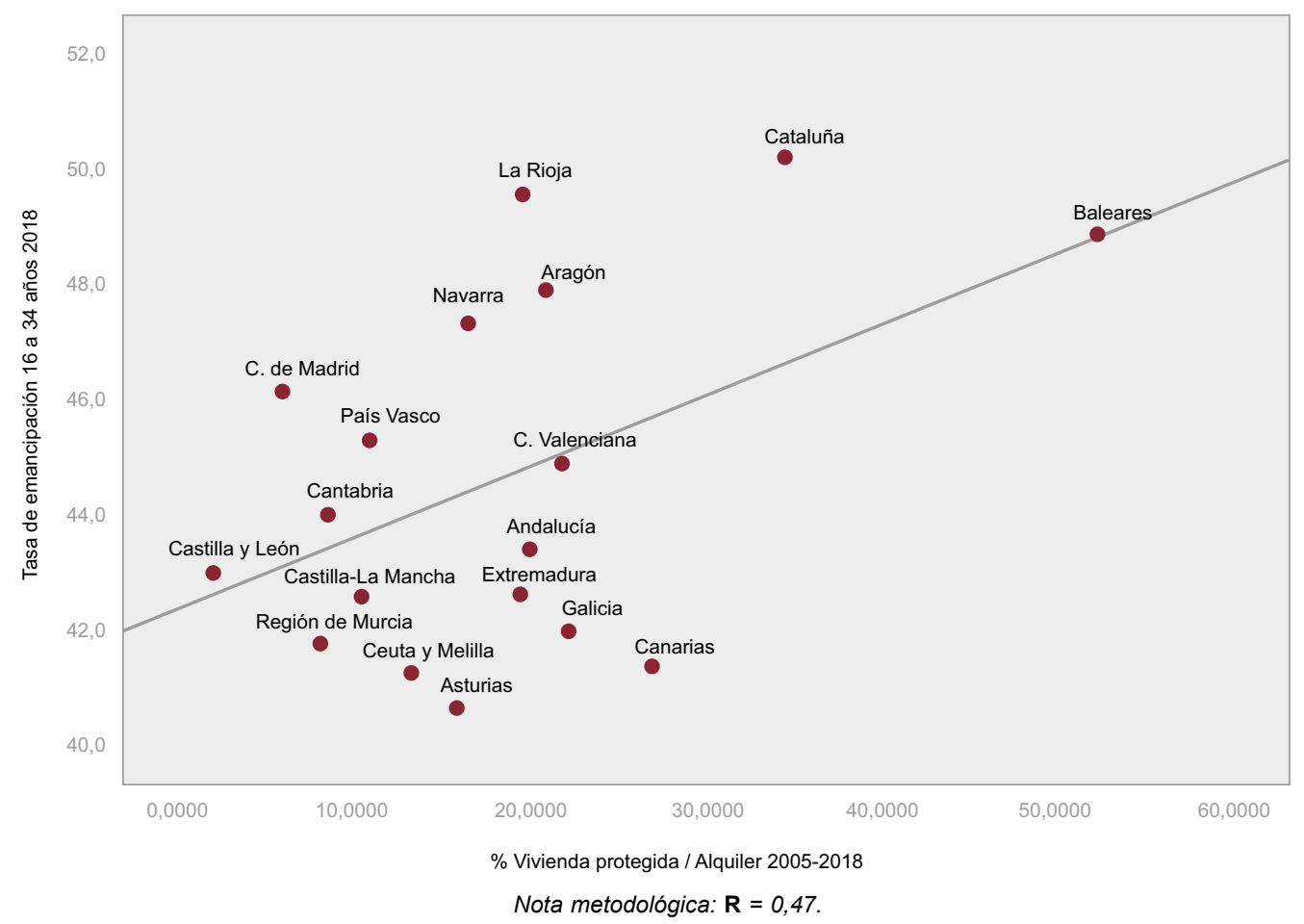

FIG. 9/ Dispersión simple tasas de emancipación y \% de viviendas protegidas en alquiler por CC. AA. España, 2018.

Fuente: elaboración propia a partir de la ENCUESTA DE POBLACIÓN ACTIVA (INE) y Estadísticas de vivienda del antiguo MINISTERIO DE FOMENTO. 
las tasas de emancipación. Aunque quede fuera del alcance de este artículo, estas tendencias residenciales apuntarían la necesidad de estudiar también otras características de las viviendas de los jóvenes (sociales y físicas) que son susceptibles de haberse visto afectadas como son los niveles de hacinamiento, la composición de los hogares o la localización de los mismos.

Cuando se analizan las diferencias territoriales a nivel de Comunidades Autónomas, la constatación de la hipótesis que liga los comportamientos residenciales de los jóvenes con la forma en la que se estructura la vivienda se hace más evidente puesto que:

Por un lado, se comprueba cómo allí dónde el precio del mercado del alquiler resulta más ventajoso con respecto a la propiedad el porcentaje de hogares jóvenes que arrienda tiende a ser mayor tal como demuestran las cifras de la Comunidad de Madrid, Cataluña o Baleares en contraposición a los casos de Extremadura, Castilla La Mancha, Región de Murcia y Comunidad Valenciana.

Por otro lado, se constata cómo el nivel de promoción de vivienda protegida en alquiler en cada Comunidad Autónoma guarda correlación con las tasas de emancipación de modo que a medida que aumenta el porcentaje de vivienda protegida en alquiler se incrementan también las tasas de emancipación con Baleares y Cataluña a la cabeza.

Estos patrones diferenciales entre Comunidades Autónomas ponen de manifiesto cómo, bajo la lógica del SPV español, existen también divergencias territoriales en función de la forma y el nivel de intervención pública de cada administración lo que demuestra la relevancia y la necesidad de analizar de manera más pormenorizada el impacto de las distintas políticas de vivienda sobre los comportamientos y sus consecuencias sobre la satisfacción de las necesidades residenciales de los jóvenes.

\section{Bibliografía}

Allen, J. \& al. (2004): Housing and Welfare in Southern Europe. London, Reino Unido, Blackwell.

ARBACI, S. (2008): Hacia la construcción de un discurso sobre la inmigración en las ciudades del sur de Europa. La política urbanística y de vivienda como mecanismos estructurales de marginación étnica residencial. ACE: Architecture, City and Environment, 8, 11-38.

BASSETT, K. \& J. SHORT (1980): Housing and Residential Structure: Alternative Approach, London, Reino Unido, Routledge \& Kegan Paul.
Boelhouwer. P. \& VAN DER HeIJden, H. (1994): Social Housing in Western Europe in the Nineties. Neth. Journal of Housing and the Built Environment, Vol. 9 (4), 331-342.

CACHÓN, L. (2004): Inmigrantes jóvenes en España. Informe de Juventud 2004, Madrid, España, Instituto de la Juventud.

CORTÉS, L. (1995): La cuestión residencial. Bases para una sociología del habitar, Madrid, España, Editorial Fundamentos.

- \& MARTíneZ, C. (2009): Los hogares jóvenes ante los retos de la independencia: el filo de la exclusión. Observatorio joven de la vivienda en España (OBJOVI), Consejo de la Juventud de la Juventud en España.

EChAVES, A. (2017a): El difícil acceso de los jóvenes al mercado de vivienda en España: precios, regímenes de tenencia y esfuerzos. Cuadernos de Relaciones Laborales, 35(1), 127-150.

- (2017b): Emancipación residencial y sistema de provisión de vivienda: la heterogeneidad autonómica del modelo español. Revista Española de Investigaciones Sociológicas, 159, 51-72.

- (2018): Emancipación residencial y sistema de provisión de vivienda en España. Hacia un análisis explicativo comparado por Comunidades Autónomas, Madrid, España, Politeya, Estudios de Política y Sociedad, $n .^{\circ} 33$, Centro Superior de Investigaciones Científicas.

— \& ECHAVES, C. (2017): Jóvenes aún más precarios: crisis económica y desigualdad laboral en España. Cuadernos de Investigación en Juventud, 2, 1-19.

ECHAVES, C. \& ECHAVES, A. (2018): Espacios habitados y vulnerabilidades socioeconómicas selectivas. ANDULI, Revista Andaluza de Ciencias Sociales, 17, 133-151.

- \& NAVARRo, C.J. (2018): Regímenes de provisión de vivienda y emancipación residencial: análisis del esfuerzo público en vivienda en España y efecto en las oportunidades de emancipación desde una perspectiva autonómica comparada. Política y Sociedad, 55(2), 615-638.

FLAQUER, LL. (2004): La articulación entre familia y el Estado de bienestar en los países de la Europa del sur. Papers, 73, 27-58.

FERRERA, M. (1995): Los estados de bienestar del sur en la Europa social. En: Sarasa, S. y Moreno, L. (eds.). El Estado de Bienestar en la Europa del Sur, Madrid, Consejo Superior de Investigaciones Científicas.

- (2010): The South European Countries, en CASTLES, F.; G. Leibfried, S.; LeWIS, J.; ObINGER, H. y Pierson, C. (ed.) The Oxford Handbook of the Welfare State, Oxford, New York: Oxford University Press.

Furlong, A. \& CARTMEL, F. \& Biggart, A. (2006): Choice biographies and transitional linearity: Reconceptualising modern youth transitions. Papers, Revista de Sociología, 225-240.

GAVIRIA, S. (2007): Juventud y familia en Francia y en España, Madrid, España, Colección "Monografías" n. ${ }^{\circ} 234$, Centro de Investigaciones Sociológicas.

GonzÁlez, Ma . J. (2000): Políticas y Estrategias Urbanas, Madrid, España, Fundamentos.

HAFFNER, M. \& al. (2009): Bridging the gap between social and market rented housing in six European 
countries? Delft, Países Bajos, Housing and Urban Policy Studies n. ${ }^{\circ} 33$, Delft University of Technology.

HARLOE, M. (1995): The People's Home: social rented housing in Europe and America, Oxford, Blackwell.

HOEKSTRA, J. (2010): Divergence in European welfare and housing systems, Delft, Países Bajos, Sustainable Urban Areas n. ${ }^{\circ}$ 38, Delft University of Technology.

JURADO, T. (1997): Un análisis regional de los modelos de convivencia de los jóvenes españoles. Las cuatro Españas de la emancipación familiar. Estudios de Juventud, 39, 17-35.

- (2003): La vivienda como determinante de la formación familiar en España desde una perspectiva comparada. Revista Española de Investigaciones Sociológicas, 103, 113-157.

- (2006): El creciente dinamismo familiar frente a la inflexibilidad del modelo de vivienda español. Cuadernos de Información Económica, 193, 117-126.

KemenY, J. (1992): Housing and social theory, Londres, Reino Unido, Routeledge.

LEAL, J. (1978): Vivienda y sociedad: el análisis sociológico del problema de la vivienda, Revista Española de Investigaciones Sociológicas, 8, 89-102.

- (2004): El diferente modelo residencial de los países del sur de Europa. El mercado de viviendas, la familia y el Estado, ARXIUS, Arxius de Ciènces Socials, 10, 11-37.

- (2018): El nuevo modelo residencial inducido por la crisis económica: el caso de Madrid. ANDULI, Revista Andaluza de Ciencias Sociales, 17, 89-108.

- \& AlguACIL, A. (2012): Vivienda e inmigración: las condiciones y el comportamiento residencial de los inmigrantes en España. En Aja, E.; Arango, J. y Oliver, J. (Eds.). La hora de la integración, Barcelona, España, Anuario de la Inmigración en España.

— \& MARTínez-DEl Olmo, A. (2017): El progresivo abandono de la política de vivienda en España. Cuadernos de Relaciones Laborales 35(1), 15-41.

LÓPEZ, A. (2008): Jóvenes en una sociedad cambiante. Demografía y transiciones a la vida adulta. Informe de Juventud 2008, Tomo I, Madrid, España, Instituto de la Juventud.

MARTínEZ-DEL Olmo, A. (2013): Sistemas de vivienda y comportamiento residencial: ¿hacia una convergencia europea?, Tesis Doctoral. Facultad de Ciencias Políticas y Sociología, Universidad Complutense de Madrid, España.

- (2018): La explosión del alquiler y las desigualdades residenciales en Madrid. ANDULI, Revista Andaluza de Ciencias Sociales, 17, 109-132.

- (2019): El sistema de vivienda del sur de Europa: ¿continuidad o ruptura? Revista Española de Sociología, 29 (1), 153-180.

MÉNDEZ, R. \& ABAD, L.D. \& ECHAVES, C. (2015): Atlas de la crisis. Impactos socioeconómicos y territorios vulnerables en España, Valencia, España, Tirant Lo Blanch.

MIRET, P. (2005): Pautas territoriales en la emancipación juvenil en España, cohortes de nacimiento 1924-1968, Papeles de Geografía, 41-42, 161-176.
- (2010): Emancipación juvenil a través de la formación de la pareja. Una comparación entre los censos de 1991 y de 2001. Papers. Revista de Sociología, 95, 757-777.

MódENES, J. A. \& LóPEZ-CoLÁs, J. (2012): El sistema residencial: un esquema conceptual para entender la relación dinámica entre población y vivienda en España, Papers de Demografía, 400, 1-30.

- (2014): Cambio demográfico reciente y vivienda en España: ¿hacia un nuevo sistema residencial? Revista Española de Investigaciones Sociológicas, 148, 103-134.

Moreno, A. \& López, A. \& Segado, S. (2012): La transición de los jóvenes a la vida adulta. Crisis económica y emancipación tardía, Barcelona, España, Colección Estudios Sociales, n. ${ }^{\circ} 34$, Obra Social "La Caixa".

NASARRE, S. (2017): Cuestionando algunos mitos del acceso a la vivienda en España, en perspectiva europea. Cuadernos de Relaciones Laborales 35(1), 43-69.

Preteceille, E. (1971): La production des grands ensembles, París, Francia, CSU Centre de Sociologie Urbaine.

PAREJA, M. (2010): El régimen de tenencia en España, en Leal, Jesús (coord.) La Política de vivienda es España (pp. 94-122). Madrid, España, Fundación Pablo Iglesias.

- \& SÁNCHEZ, M. T. (2012): La Política de Vivienda en España: lecciones aprendidas y retos de futuro. Revista Galega de Economía, 21 (2), 1-32.

PATón, J. M. (2007): Emancipación juvenil y políticas de vivienda en Europa. Arquitectura, Ciudad y Entorno, año II, 5, 523-553.

REQUENA, M. (2002): Juventud y dependencia familiar en España. Revista de Estudios de Juventud, 58,19-32.

RODRíGUEZ, J. (2010): Demanda de vivienda y esfuerzo económico. En Leal, J. (coord.) La Política de vivienda es España (pp. 38-65). Madrid, España, Fundación Pablo Iglesias.

- (2017): Las viviendas que pudieron hundir la economía española. La caída del mercado de la vivienda y sus consecuencias. Cuadernos de Relaciones Laborales, 35(1), 71-99.

RoNALD, R. (2007): Comparing Homeowner Societies: Can we Construct an East-West Model? Housing Studies, 22, 473-493.

Stone, J.\& BerRington, A. \& FALKIngham, J. (2010): How far have transitions to adulthood changed in the last decade? Evidence from the United Kingdom Labour Force Survey, Centre for Population Change, Working Paper 5/2010, 1-32.

VINUESA, J. (2008): Propuesta de un método para el análisis demográfico de la emancipación de los jóvenes. Scripta Nova: Revista electrónica de geografía y ciencias sociales, 12, 256-280. 